\title{
Thermal Lag Correction on Slocum CTD Glider Data
}

\author{
Bartolomé Garau, ${ }^{*}$ Simón Ruiz, ${ }^{+}$Weifeng G. Zhang, ${ }^{\#}$ AnANda Pascual, ${ }^{+}$ \\ EMMA HESLOP, ${ }^{+}$JOHN KERFOOT, ${ }^{@}$ AND JOAQUÍN TINTORÉ*,+ \\ * SOCIB, Mallorca, Spain \\ ${ }^{+}$IMEDEA (CSIC-UIB), Mallorca, Spain \\ \# Woods Hole Oceanographic Institution, Woods Hole, Massachusetts \\ @ IMCS, Rutgers, The State University of New Jersey, New Brunswick, New Jersey
}

(Manuscript received 28 October 2010, in final form 30 March 2011)

\begin{abstract}
In this work a new methodology is proposed to correct the thermal lag error in data from unpumped CTD sensors installed on Slocum gliders. The advantage of the new approach is twofold: first, it takes into account the variable speed of the glider; and second, it can be applied to CTD profiles from an autonomous platform either with or without a reference cast. The proposed methodology finds values for four correction parameters that minimize the area between two temperature-salinity curves given by two CTD profiles. A field experiment with a Slocum glider and a standard CTD was conducted to test the method. Thermal lag-induced salinity error of about 0.3 psu was found and successfully corrected.
\end{abstract}

\section{Introduction}

Underwater gliders are a special case of underwater autonomous vehicles, which are designed to observe vast areas of the interior ocean (Stommel 1989). Buoyancy control allows gliders to achieve vertical motions in the water column. In addition, using their hydrodynamic shape and small fins, they can project the vertical buoyancy force to move horizontally. This combination of vertical and horizontal movements makes the glider follow a sawtooth pattern. The Slocum glider, manufactured by Teledyne Webb Research Corporation, has a nominal horizontal speed of about $0.4 \mathrm{~m} \mathrm{~s}^{-1}$. Two Slocum models are available - a coastal version that is limited to a maximum depth of $200 \mathrm{~m}$, and a deep version that can reach depths of $1000 \mathrm{~m}$.

The Instituto Mediterráneo de Estudios Avanzados (IMEDEA) has been operating a small fleet of Slocum gliders since 2005, comprising one coastal and three deep gliders. To date, the IMEDEA gliders have gathered $\sim 9000$ conductivity-temperature-depth (CTD) profiles in the western Mediterranean, including the sampling in very energetic areas, such as the Alboran Sea with

Corresponding author address: Bartolomé Garau, ICTS SOCIB Parc Bit, Naorte, Bloc A 2p. pta 3, Palma de Mallorca, Spain. E-mail: tgarau@socib.es strong horizontal and vertical density gradients. With the increasing use of these new autonomous platforms equipped with CTD sensors, among others, new issues arise related to the processing and quality control of the data.

The hydrographic variables of temperature and salinity are used by most of the oceanographers, and only temperature is observed with a specific sensor. Salinity is, in fact, inferred from measured conductivity and temperature using the state equations (UNESCO 1981). To obtain accurate salinity data, the CTD instruments require corrections for temporal and spatial mismatches in the temperature and conductivity sensor responses. A temperature sensor measures seawater temperature outside of the conductivity cell while a conductivity sensor measures seawater conductivity inside of the conductivity cell. All conductivity cells have mass and, therefore, the capacity to store heat. When a conductivity cell moves through temperature gradients, heat is lost to/gained from the surrounding water (based on gradient direction). Depending on cell design, varying amounts of the heat stored in (released from) the cell body warm (cool) the water within the cell, changing its conductivity. Because temperature sensors are located outside the conductivity cell, the temperature reported by the CTD will be slightly different from the actual temperature inside the conductivity cell. Therefore, when those measurements of temperature and conductivity are used in the salinity 
equation, the computed salinity will be erroneous, especially when crossing strong temperature gradients (thermocline). This issue, known as the thermal lag effect, has been widely studied in the past as applied to standard CTD probes. Lueck and Picklo (1990) proposed a numerical model for the thermal inertia of Sea-Bird conductivity cells. By analyzing a temperature-salinity $(T-S)$ diagram, Morison et al. (1994) evaluated the correction to the thermal lag error.

The Sea-Bird CTD installed on Slocum gliders has new problems that make it difficult to apply traditional techniques without modifications. In particular, (i) the CTD on board Slocum gliders is unpumped, and therefore the flow speed depends on glider surge speed; (ii) the gliders' CTD sampling has a low temporal resolution $(\sim 0.5 \mathrm{~Hz})$ in comparison to the high resolution of CTD sampling as operated from ships; and (iii) the glider CTD sampling interval is irregular.

In this work, we propose a new methodology for the thermal lag correction for unpumped Sea-Bird CTD sensors installed on Slocum gliders, consisting of a modification of traditional correction methods to take into account the variable speed of the glider. The method is tested in a specific calibration experiment in the western Mediterranean.

\section{A new methodology}

As stated before, the salinity errors are produced because of the mismatch between temperature (measured outside the conductivity cell) and conductivity (measured inside the conductivity cell). To solve this inconsistency, two approaches can be followed-either estimating the conductivity that would have been measured outside the conductivity cell (without thermal mass inertia), or estimating the temperature that would have been measured inside the conductivity cell. Both approaches use the scheme described in Morison et al. (1994) and Mensah et al. (2009).

In the first approach, the correction $\left(C_{T}\right)$ is applied to conductivity and the correction at $\operatorname{scan} n\left(C_{n}\right)$ is as follows:

$$
C_{T}(n)=-b C_{T}(n-1)+\gamma a[T(n)-T(n-1)],
$$

where $T$ is measured temperature and $\gamma$ is the sensitivity of conductivity to temperature, an estimated value given by the manufacturer, while $a$ and $b$ are two coefficients computed as follows:

$$
\begin{aligned}
& a=\frac{4 f_{n} \alpha \tau}{1+4 f_{n} \tau} \text { and } \\
& b=1-\frac{2 a}{\alpha},
\end{aligned}
$$

where $f_{n}$ is the sampling frequency, and $\alpha$ and $\tau$ are the amplitude of the error and time constant, respectively. This conductivity correction $\left(C_{T}\right)$ is added to the measured conductivity.

The second approach tries to estimate the temperature inside the conductivity cell for the sole purpose of calculating salinity with measured conductivity, and the temperature correction $\left(T_{T}\right)$ is computed using the following expression:

$$
T_{T}(n)=-b T_{T}(n-1)+a[T(n)-T(n-1)],
$$

where coefficients $a$ and $b$ are computed by also following Eqs. (2) and (3). In this case, the correction is subtracted from the measured temperature. This approach offers an advantage over the first one, because it does not rely on the estimated sensitivity $\gamma$, and it is also computationally more efficient because $\gamma$ does not need to be computed.

Morison et al. (1994) showed that there is a relation between the correction parameters $\alpha$ and $\tau$ and the flow speed through the conductivity cell. In the case of pumped CTDs, the flow speed is either known or, at worst, can be estimated by observing the misalignment between the sensors' signals. The flow speed is then assumed to be constant and the correction parameters $\alpha$ and $\tau$ are also constant.

The approach in this paper proposes a generalization of the method developed by Morison et al. (1994), where the relation between $\alpha$ and $\tau$ and the flow speed is computed throughout the profile, so that the assumption of constant flow speed is no longer required. Following Morison et al. (1994), the relation between the correction parameters and the flow speed is

$$
\begin{aligned}
& \alpha(n)=\alpha_{o}+\alpha_{s} V_{f}(n)^{-1} \text { and } \\
& \tau(n)=\tau_{o}+\tau_{s} V_{f}(n)^{-1 / 2},
\end{aligned}
$$

where $V_{f}$ is the velocity of the flow, based on the glider surge speed, which is variable over the profile. Parameters with subscript $o$ and $s$ are the offsets and slopes for $\alpha$ and $\tau$, respectively. This model holds as long as the flow speed is bounded within a narrow range, which is true for the experiments performed. For wide ranges of flow speed variation, other models might be more appropriate (Eriksen 2009). In our approach, the correction relies on finding values for the four parameters: the offsets $\alpha_{o}, \tau_{o}$, and the slopes $\alpha_{s}, \tau_{s}$. These are obtained by minimizing an objective function that measures the area between two $T-S$ curves given by two CTD profiles, one upcast and one downcast. The main hypothesis is that the 


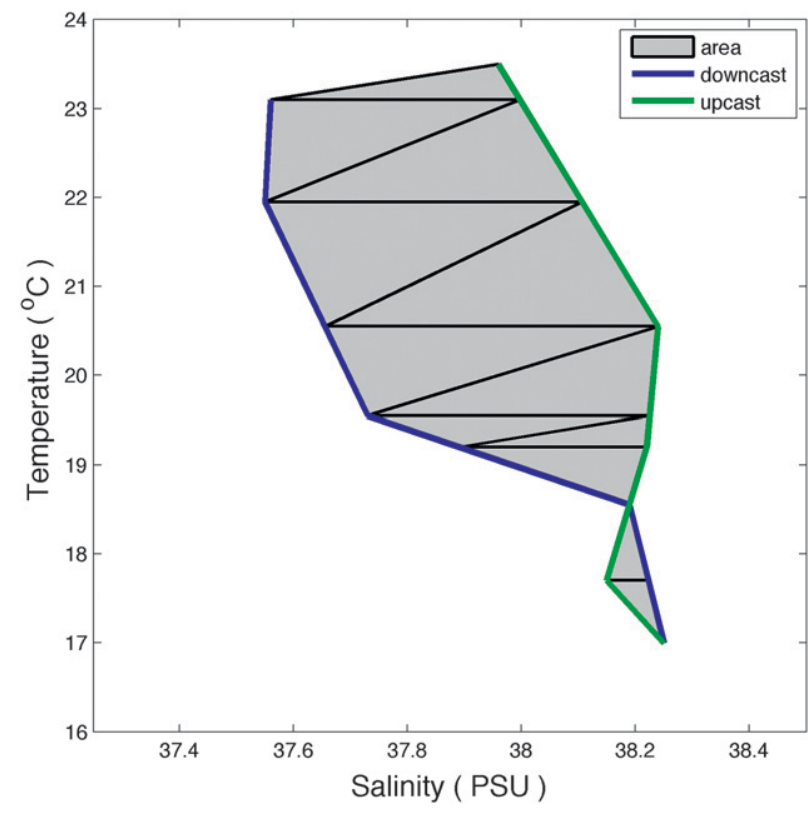

FIG. 1. Schematic and synthetic $T-S$ diagram showing how a polygon is built from two profiles and how its area is computed through the summation of the forming triangles.

compared profiles correspond to the same water mass (assuming a low horizontal advection). In each iteration of the minimization process, a polygon is built using the two profiles to describe its perimeter. The polygon area is computed through the summation of the areas of the forming triangles (Fig. 1), avoiding problems with concavities and self-intersections. The minimization is carried out using the optimization toolbox from MATLAB, finding the minimum of a constrained nonlinear multivariable function by means of a medium-scale optimization that uses a sequential quadratic programming (SQP) method.

Two approaches can be followed in order to apply this correction. The first one relies exclusively on glider data, and the glider CTD profiles are corrected with the set of glider-derived parameters. The second involves having an outside CTD reference (e.g., ship CTD), which can be used as a ground truth. In this approach, we assume a typical glider deployment from a vessel equipped with a CTD probe. In such a situation, a ship CTD cast can be performed at the same time and in the same area of the glider first dives. This information can then be used as independent data to adjust the first glider profiles. Similarly, the same procedure can be applied when recovering the glider. Other typical situations for this approach would be the case of multiparametric experiments (Pascual et al. 2010) where gliders are combined with independent observations, such as ship CTD casts, XBTs, and water samples, among others.

\section{Calibration experiment}

A specific experiment was dedicated to evaluate the new thermal lag correction proposed above. The field work was conducted in summer, when the water column was strongly stratified. Moreover, the horizontal advection in the study area (Fig. 2a) is very low, especially in summer (Pinot et al. 2002). Simultaneous CTD profiles from gliders and ship were carried out in an area of $1 \mathrm{~km} \times 1 \mathrm{~km}$. The CTD casts from ship were conducted approximately at the horizontal midpoint of each glider dive (Fig. 2b), which ensures sampling of the same water masses (assuming low horizontal advection in the area).

\section{a. CTD glider data}

We used a Slocum coastal glider equipped with an unpumped Sea-Bird CTD sensor (SBE41 modified) and bio-optical fluorescence and turbidity sensors. The specific mission of the glider consisted of a yo-yo path, diving to $80 \mathrm{~m}$ and then climbing to $5 \mathrm{~m}$ with a pitch at $\pm 26^{\circ}$, thus, performing a $\mathrm{W}$-shaped vertical trajectory. The sampling frequency (scan rate) was $0.5 \mathrm{~Hz}$.

\section{b. CTD ship data}

The CTD casts from ship were performed with a Sea-Bird Electronics SBE25, which had been recently laboratory calibrated. This probe uses a temperatureconductivity (TC) duct and a pump that maintains a constant flow rate. For this experiment the sampling frequency (scan rate) was $8 \mathrm{~Hz}$.

\section{Results}

\section{a. CTD comparison between glider and ground truth (ship)}

CTDs temperature profiles, from both the ship and glider, show a mixed upper layer $(\sim 25 \mathrm{~m})$ with a temperature of $25.8^{\circ} \mathrm{C}$. Between 25 and $60 \mathrm{~m}$, a strong thermocline is observed with temperature ranging from $25.8^{\circ}$ to $15^{\circ} \mathrm{C}$. Below $60 \mathrm{~m}$, the temperature remains almost constant at $15^{\circ} \mathrm{C}$. Very small differences are observed in temperature profiles from the glider and ship. Conversely, the salinity profiles show significant differences between 10 and $70 \mathrm{~m}$, with maximum discrepancies of about 0.3 psu at $30-\mathrm{m}$ depth (Fig. 3). Moreover, it is noted that the glider data overestimate (underestimate) salinity when performing a downcast (upcast) because of the heating (cooling) of the water inside the conductivity cell. These thermal lag effects on salinity profiles translate into unrealistic inversions in the density profiles (not shown). 
(a)

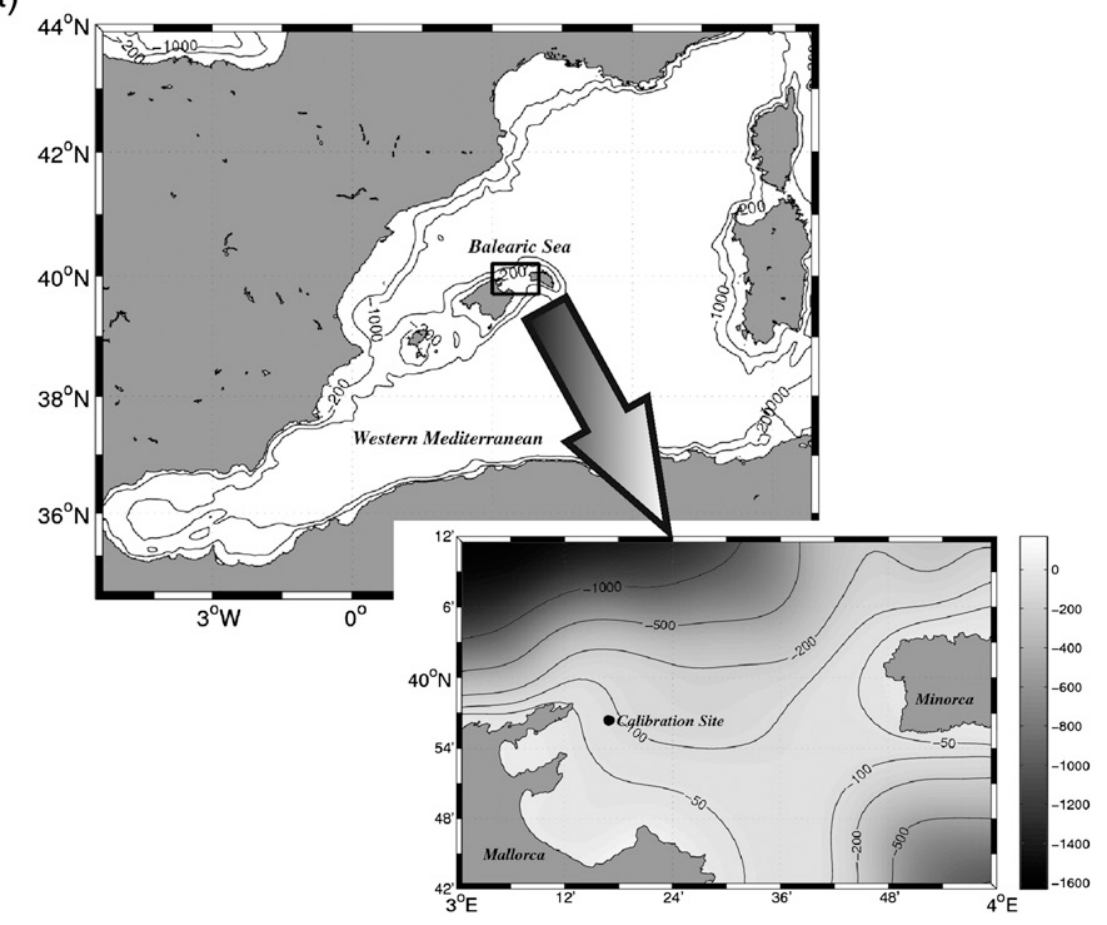

(b)

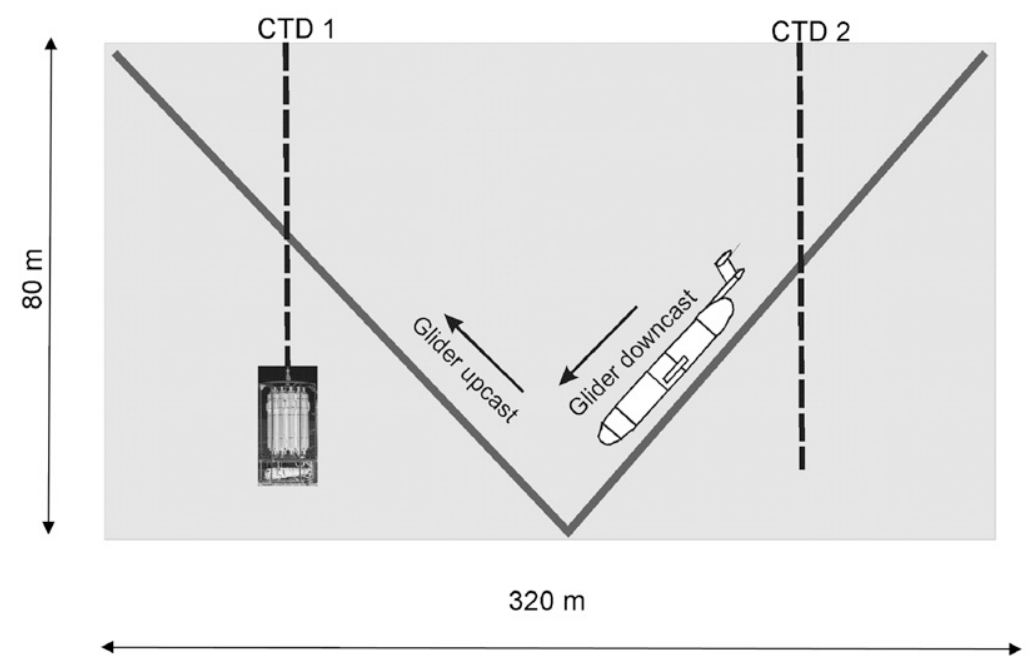

FIG. 2. (a) Map of the area (northeast of Mallorca, Spain, in the western Mediterranean) for the thermal lag correction experiment in 2008. (b) Schematic view of the CTD and glider sampling design.

After correcting the thermal lag error (see parameters in Table 1), the glider salinity profile indicates a significantly improved alignment with the ship reference salinity profile. At $30 \mathrm{~m}$ the difference in salinity is reduced to 0.04 psu (Fig. 3). Statistical median values of the parameters have been computed from the whole set of parameters obtained from the different corrections. These statistical values prove that the corrected salinity profiles are in good agreement (with a maximum difference of
0.04 psu as well) with the reference profile from the ship CTD (Fig. 3).

\section{b. CTD glider downcast versus upcast}

Figure 4 shows the $T-S$ diagram of the glider downcast against the upcast. In this case, the thermal lag correction clearly reduces the salinity spikes and the $T-S$ hysteresis, either using upcast-downcast pairs or statistically derived parameters, shown in Table 1 . This is promising because 
(a)
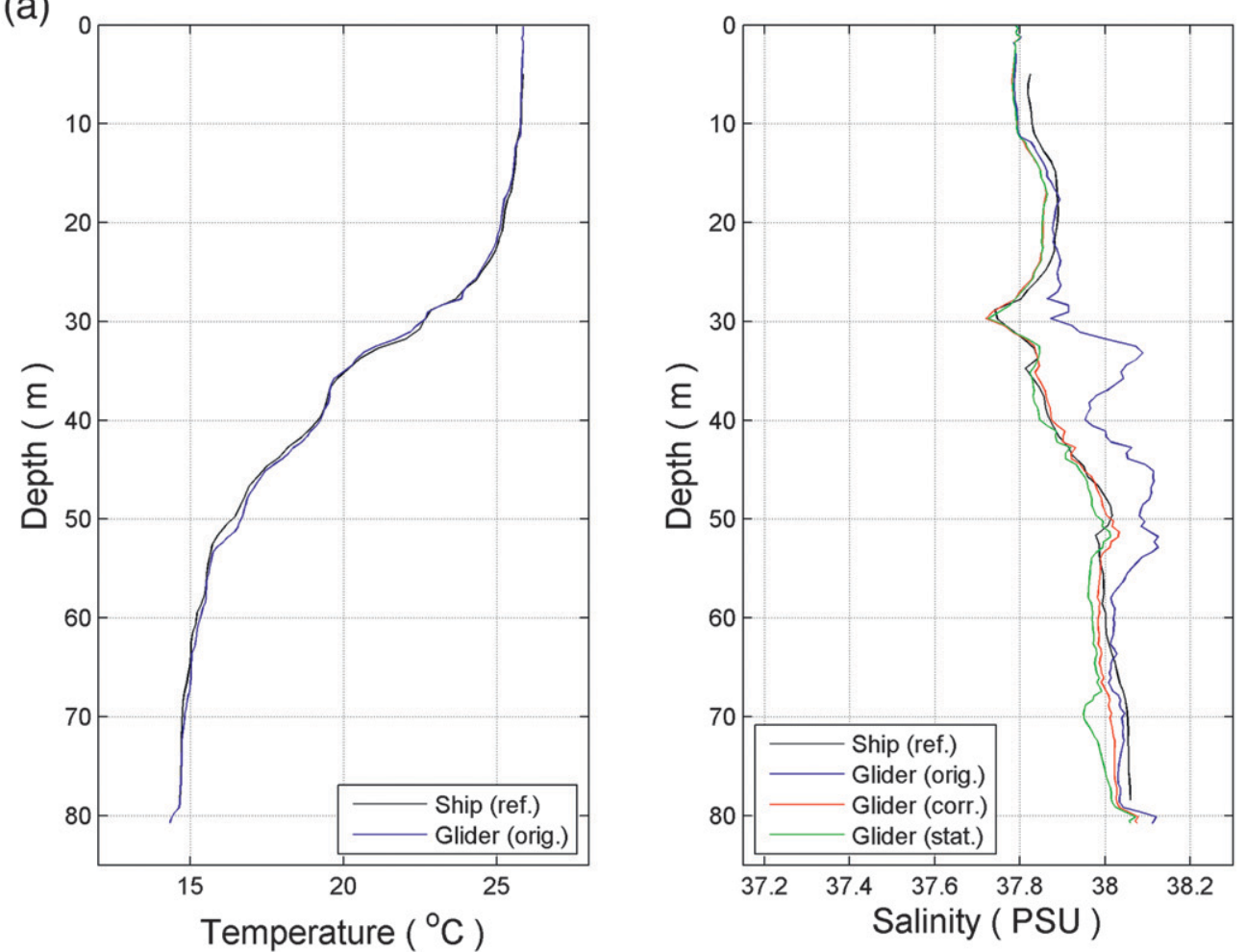

(b)
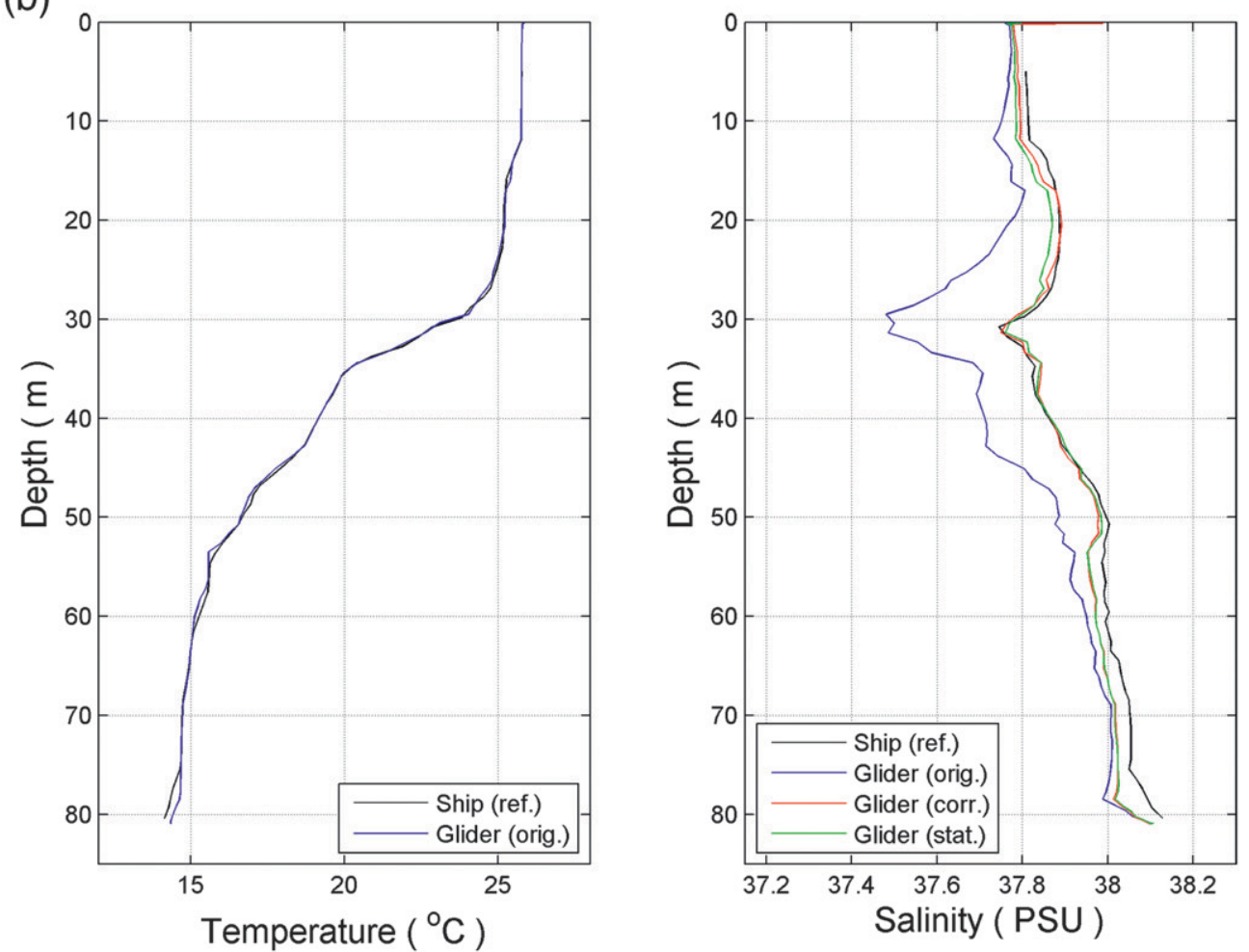

FIG. 3. (left) Temperature and (right) salinity profiles from glider and reference CTD. (top) Downcast and (bottom) upcast. The ship profile (black lines) is considered as reference. Reference: ref, original: orig., corrected with the objective method: corr, and corrected with statistical median parameters: stat. 
TABLE 1. Correction parameters $\left(\alpha_{o}, \alpha_{s}, \tau_{o}\right.$, and $\left.\tau_{s}\right)$ obtained from CTD pairs of glider vs ship, glider downcast vs glider upcast, and median.

\begin{tabular}{lccrc}
\hline \hline & $\alpha_{o}$ & $\alpha_{s}$ & \multicolumn{1}{c}{$\tau_{o}$} & \multicolumn{1}{c}{$\tau_{s}$} \\
\hline Ship CTD vs glider & 0.1301 & 0.0003 & 9.3322 & 5.0818 \\
& 0.0971 & 0.6365 & 12.5490 & 3.7062 \\
& 0.1790 & 0.0000 & 7.0716 & 2.7460 \\
Glider downcast vs upcast & 0.1818 & 0.0407 & 7.0283 & 2.7671 \\
& 0.1256 & 0.0054 & 10.0249 & 4.6128 \\
Median & 0.1354 & 0.0361 & 9.7492 & 4.7259 \\
& 0.1328 & 0.0208 & 9.7492 & 4.6128 \\
\hline
\end{tabular}

it demonstrates that, in the case of no CTD ship reference, the error in salinity profiles induced by the thermal lag effect can be reduced significantly through the minimization of the area of two consecutive profiles from gliders. This approach has been successfully applied in glider missions performed in the western Mediterranean where there was no ship CTD reference (Ruiz et al. 2009; Bouffard et al. 2010). In all of these missions, the new methodology significantly improved the salinity correction with respect to the original Morison et al. (1994) methodology. In Fig. 5, several bands distorting the halocline are present even when using the Morison et al. correction method (which is the most common approach to correct the thermal lag effects), while they are significantly reduced when using our approach. A quantitative comparison between Morison et al. and the proposed methods was performed using the areas in a $T-S$ diagram of 220 paired downcast-upcast profiles from a glider mission. The mean area computed with the proposed method was 3 times lower than the one obtained with the Morison et al. approach.

\section{Concluding remarks}

A new methodology has been proposed for the thermal lag correction of salinity data from unpumped CTD sensors installed on Slocum gliders. The advantage of the new approach with respect to other studies is twofold: (i) it takes into account the variable speed of the glider, and (ii) can be applied using a ship CTD salinity profile as reference or imply just an upcast-downcast CTD sequence from the autonomous platform itself. A field experiment with a Slocum glider and a standard ship's CTD was conducted in the western Mediterranean, proving that the proposed method is capable of successfully correcting a thermal lag-induced salinity error, in this case of approximately 0.3 psu. Further studies could be performed to characterize and improve the model of conductivity cell flushing speed, with both laboratory and in situ experiments (Eriksen 2009).

Although manufacturers of marine instruments are developing new low-power, constant-pumped flow CTD for autonomous underwater vehicles, which will presumably

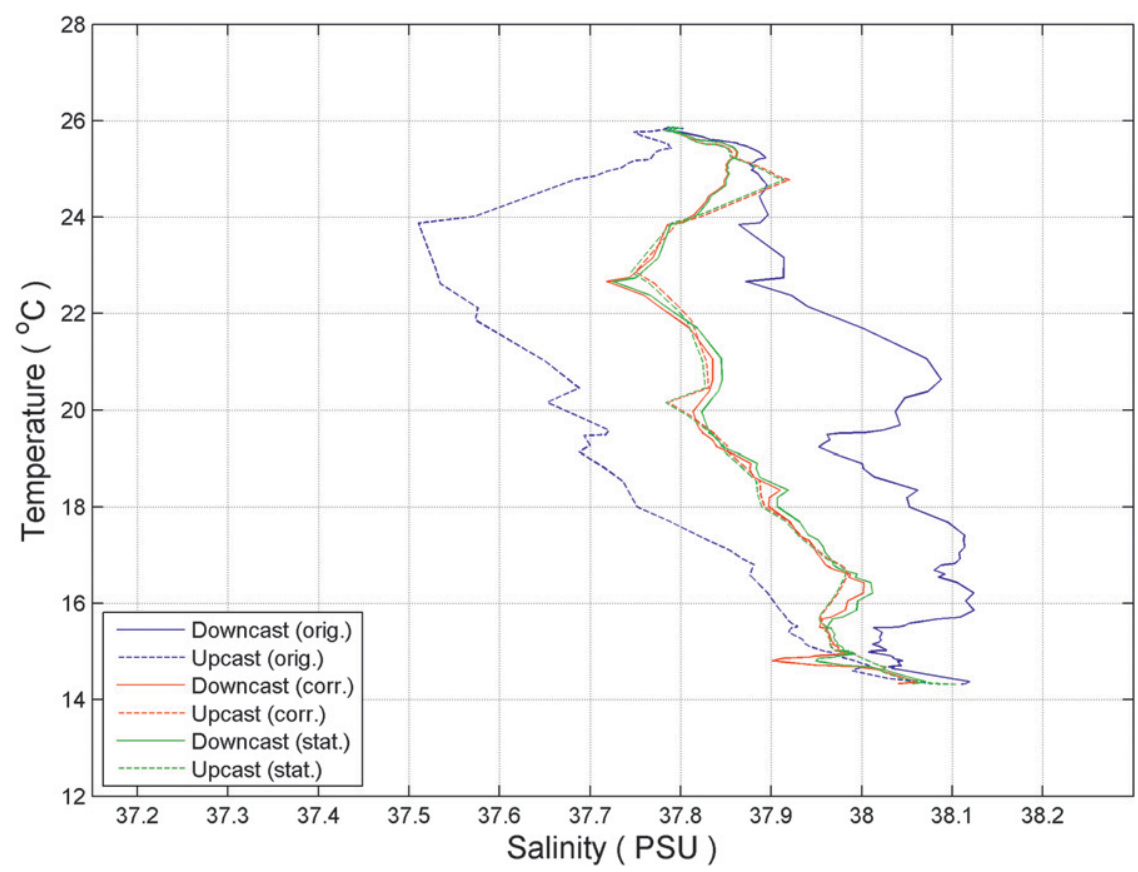

FIG. 4. Temperature-salinity diagram from glider CTD (downcast vs upcast) gathered during the calibration experiment. Abbreviations in the legend are same as those in Fig. 3. 

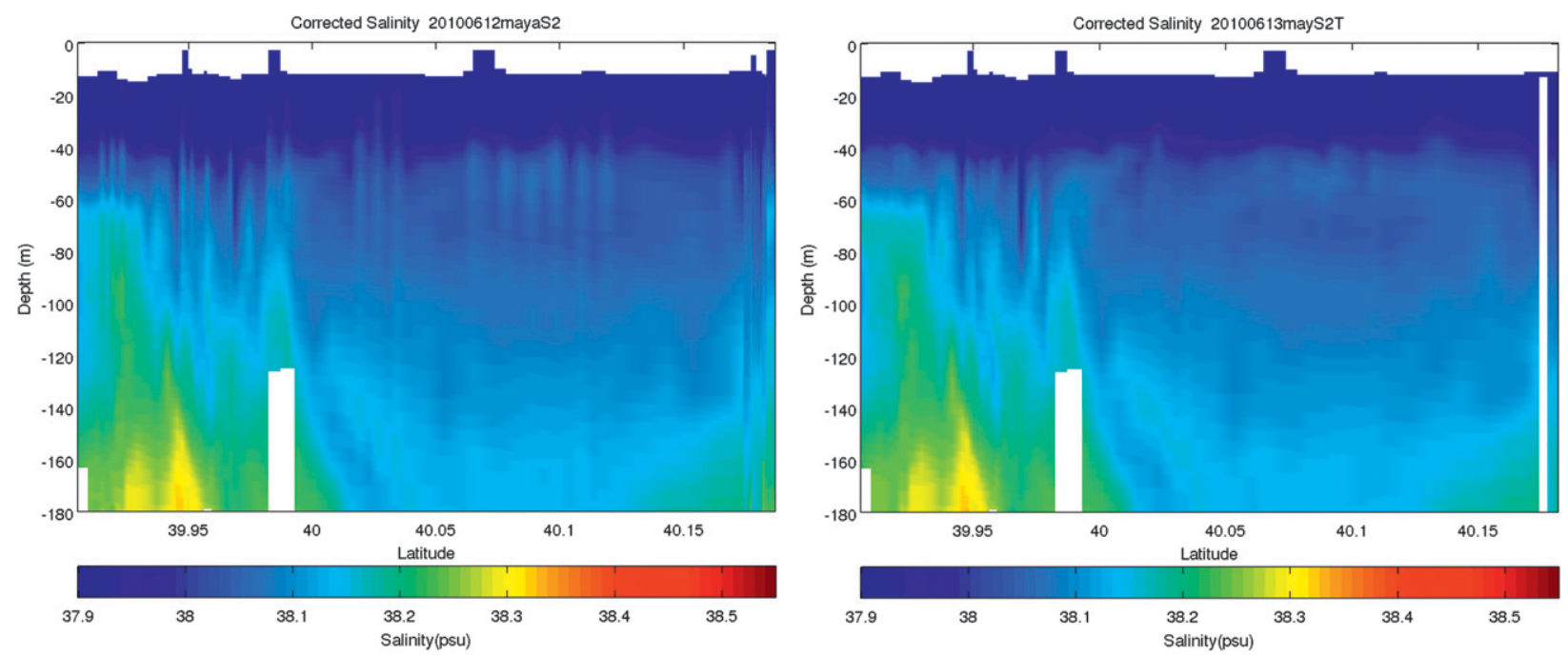

FIG. 5. Corrected salinity using parameters from (left) Morison et al. (1994) and (right) the new proposed methodology (right).

improve the accuracy of temperature and salinity data (Sea-Bird Electronics 2008), at present gliders with unpumped CTD sensors are being routinely operated around the world and new procedures to correct the data are urgently needed. Thus, specific corrections such as the thermal lag described in this work, as well as the application of standard quality control procedures (e.g., flagging $T$ and $S$ outliers based on historical data and density inversions) are a prerequisite to include the datasets from these autonomous platforms in future multisensor observing networks.

\section{Availability of the code}

The thermal lag correction code described in this paper has been implemented as a MATLAB toolbox, and it is documented and freely available online (http:// www.socib.es/ glider/doco/gliderToolbox/ctdTools/ thermalLagTools).

Acknowledgments. This work is part of the SINOCOP and GliderBal projects funded by CSIC and Govern Balear, respectively. The authors thank the IMEDEATMOOS glider team for their support during the calibration experiment and Prof. Charles C. Eriksen for his comments and suggestions during the visiting period at IMEDEA in September 2010. Special thanks to Dr. Scott Glenn for his comments during the author's visit to the Coastal Ocean Observation Laboratory (COOL) at Rutgers, The State University of New Jersey. Partial support from SOCIB (Balearic Islands Coastal Observing and Forecasting System) is also acknowledged.

\section{REFERENCES}

Bouffard, J., A. Pascual, S. Ruiz, Y. Faugère, and J. Tintoré, 2010: Coastal and mesoscale dynamics characterization using altimetry and gliders: A case study in the Balearic Sea. J. Geophys. Res., 115, C10029, doi:10.1029/2009JC006087.

Eriksen, C. C., 2009: Salinity estimation using an un-pumped conductivity cell on an autonomous underwater glider. Extended Abstracts, Fourth EGO Conf., Larnaca, Cyprus, EGO, P9.

Lueck, R. G., and J. J. Picklo, 1990: Thermal inertia of conductivity cells: Observations with a Sea-Bird cell. J. Atmos. Oceanic Technol., 7, 756-768.

Mensah, V., M. Le Menn, and Y. Morel, 2009: Thermal mass correction for the evaluation of salinity. J. Atmos. Oceanic Technol., 26, 665-672.

Morison, J., R. Andersen, N. Larson, E. D’Asaro, and T. Boyd, 1994: The correction for thermal-lag effects in Sea-Bird CTD data. J. Atmos. Oceanic Technol., 11, 1151-1164.

Pascual, A., S. Ruiz, and J. Tintoré, 2010: Combining new and conventional sensors to study the Balearic Current. Sea Technol., $51(7), 32-36$.

Pinot, J.-M., J. L. López-Jurado, and M. Riera, 2002: The CANALES experiment (1996-98). Interannual, seasonal, and mesoscale variability of the circulation in the Balearic Channels. Prog. Oceanogr., 55, 335-370.

Ruiz, S., A. Pascual, B. Garau, Y. Faugere, A. Alvarez, and J. Tintoré, 2009: Mesoscale dynamics of the Balearic Front, integrating glider, ship and satellite data. J. Mar. Syst., 78, S3-S16, doi:10.1016/j.jmarsys.2009.01.007.

Sea-Bird Electronics, cited 2008: Glider payload CTD (preliminary). [Available online at http://www.seabird.com/products/spec_ sheets/GliderPayloadCTDdata.htm.]

Stommel, H., 1989: The SLOCUM mission. Oceanography, 19, $22-25$.

UNESCO, 1981: Tent report of the Joint Panel on Oceanographic Tables and Standards. UNESCO Tech. Papers in Marine Science 36, $24 \mathrm{pp}$. 